\title{
The Innovation Binder Approach: a guide towards a social-technical balanced pervasive health system
}

\author{
Jacobs, A.*, Duysburgh, P.*, Ongenae, F**, Ackaert A.**, Bleumers, L*. \& \\ S. Verstichel $* *$ \\ *iMinds - SMIT (Vrije Universiteit Brussel) name.surname@vub.ac.be \\ **iMinds - IBCN (Universiteit Gent) name.surname@ intec.UGent.be
}

Pervasive health systems aim to support society with the many challenges our healthcare system is facing today. Embedding systematically social choices in the Research and Development process (R\&D) is therefore essential. In this chapter the 'Innovation Binder' approach is presented: a procedure to confront multiple viewpoints from user/social, technology and business perspective, to make choices (e.g. target groups, practices, actors, messages, means, steps, procedures, technologies) more explicit and coordinate the team to work together to a common abstract goal (e.g. home monitoring system to support ambient assistive living) with a lot of unknown viable options. The spine of our approach is the iterative use of scenarios and personas with different finalities and discussing them iteratively in team. It enables a parallel research track of social and technical R\&D activities by coordinating mutual dependencies and uncertainties. We illustrate this approach with concrete examples from past and present $R \& D$ projects in the pervasive healthcare domain. This approach can help other R\&D teams, convinced of the value of interdisciplinary work, to create desired pervasive health systems for multiple users.

\section{Introduetion}
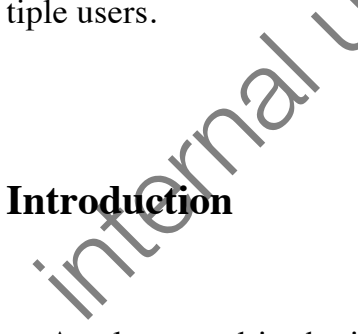

As also stated in the introductory chapter of this book (Ziefle, Röcker \& Holzinger, 2014), pervasive health systems aim to support society with the many challenges our healthcare system is facing today. We search for systems that are truly supporting this transformation of healthcare organizations (e.g., self care, relying more on local teams, increase of quality with same amount of money and people). Therefore, embedding social choices systematically in the Research and Development process $(\mathrm{R} \& \mathrm{D})$ is essential. These challenges are even more present in $\mathrm{R} \& \mathrm{D}$ of pervasive health systems. At the one, hand due to the characteristics of 
pervasive technologies (automation, delegating control, remote monitoring, massive big data, etc.) this embedding is pivotal, at the other hand because health is a domain dealing with vulnerable people, supported by people delivering care with scarce resources.

In this chapter, the 'Innovation Binder' approach is presented. The approach is a reaction to our need for a tool supporting interdisciplinary collaboration when developing new pervasive health systems. IT-innovation in healthcare is by default highly multidisciplinary, since innovation in healthcare requires a combination of methods and insights from multiple disciplines (van Bemmel, 2008). We wanted to create a procedure to confront multiple viewpoints, social and technical, to make choices (regarding, e.g., target groups, practices, actors, messages, means, steps, procedures, technologies) more explicit and coordinate the teamwork on a common, but abstract goal (e.g. home monitoring system to support ambient assistive living) with a lot of unknown viable options.

Our projects can be labeled as pre-competitive research to davelop new health ICT systems, joining Social Sciences (Soc) with Informatics \& Engineering (I\&E). Besides academic researchers, these projects typically involve people from care organizations, as well as the private sector. This diversity in project partners is seen as necessary to take the complex healthcare context into consideration during development, and adequately show how pervastve technologies can add values for multiple user roles.

The spine of our approach is the iterative use of scenarios and personas with different finalities and draws on discassing them iteratively in team. These scenarios are boundary objects that organize the process (e.g., different research activities using them, referred to during meetings). The general use and creation of scenarios and personas in the Human Computer Interaction field is well described (Bødker, 2000; Carroll, 2000). In short, scenarios are narratives trying to depict the central practices in context in relation to the technology under development. In later sections we discuss them in-depth.

We try to develop an innovation process that goes beyond the current limits of user-centered design, which is currently often limited to front end research. Equally, the 'innovation binder' approach facilitates a prolongation of the continuous integration process from back-end development towards the first level of deployment (first uses of the software). In other words, the approach helps to overcome the waiting game between technical and social output. It enables a parallel research track of social and technical R\&D activities by coordinating mutual dependencies and uncertainties.

We illustrate this approach with concrete examples from several past and present R\&D projects in the pervasive healthcare domain. This approach can help other R\&D teams, convinced of the value of interdisciplinary work, to create desired pervasive health systems for multiple users. It is a way of guiding the many choices a team should take, taking into account multiple voices, towards a valuable solution for both business and society. 


\section{Glossary: overall picture and terminology}

In this part a visual overview is given of the Innovation Binder approach (Figure 1). The rest of the chapter revolves around this picture. Before we do that, we give a short overview of the most important terms, and how we use them.

- SCOT: (Social Construction of Technology Theory) it is a framework in Science and technology studies, that emphasis the role of social processes (non linearity, power, etc.) at play when developing technology (Bijker 1997; Rip et al. 1995).

- Boundary object: an arrangement of collaboration without prior consensus between different groups. For example a concept or a drawing (Star 2010).

- Pre-competitive research: research aiming to develop demonstrating technology to be applied and used 5-10 years in the future (Limonard \& Koning 2005)

- Care domain and organizations: the broad domain of healthcare and its organizations

- Technology providers: companies developing and providing healthcare technology

- Current practices: the way people are used to do things in their everyday context, the way activities are interwoven in a social domain (Schatzki 1997)

- Future practices: imagined everyday practices in the future

- (Technical) components and communication: software components or software modules or units in the system (also referred to as 'building blocks')

- Architecture: the design of how the components are connected (also: 'software architecture')

- Technology roadmaps: the forecast of a technological development (Garcia \& Bray 1997).

Scenario : a believable narrative, usually set in the future of a person's experience as he or she engages with a product or a service (Martin \& Harrington, 2012, p152)

Persona: Cooper (2004, p. 123) defines a persona as: 'A precise description of our user and what he wishes to accomplish'. It is a fictive character based on user research insights, which serve as characters in the scenarios

- Use case: describes user tasks and the specific functions a technology offers an end user, without detailed attention to context and experiences (Bødker \& Christiansen 1994).

- TechCards: describes in a generic way the technical components that the different partners are working on 
- Update: the act of performing a new iteration on TechCards, scenarios,

- Concept and proof of concept (POC): A concept is an idea of the product or service, the proof of concept is the demonstration of the feasibility of a concept

- Co-creation: activities in which users and stakeholders are involved in concept design

- Evaluation: Concepts or POC's are evaluated together with users

- Developing and testing: creating technical solutions and performing technical evaluations of the components, concepts or POC

- Continuous integration : method to improve quality and delivery time of software developed in co-development teams by maintaining a common software code repository and supporting revision control (Fowler, 1999). 

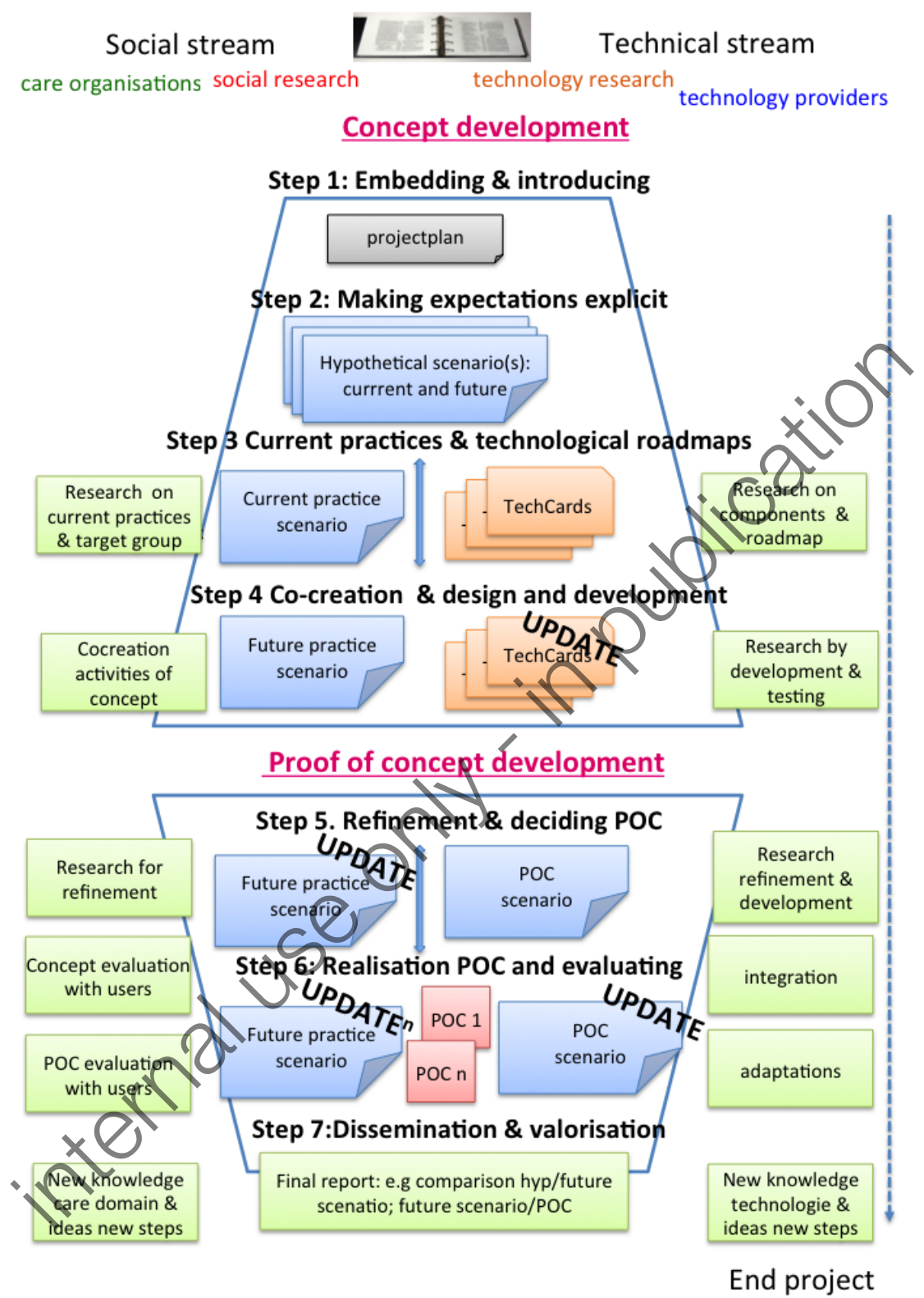

Fig. 1 Innovation Binder Approach 


\section{State-of-the-art of the innovation binder approach}

\section{Prior art or the sources of inspiration for this approach}

In this part we want to show the footage taken from previous work. First we will frame our approach within the realm of the Social Construction Of Technology theory (SCOT) within the science and technology studies. Next, the needs and problems that rise with interdisciplinary work are briefly discussed. We will situate our approach within the tools that have been developed within the fields of Human Computer Interaction (HCI) and Participatory Design (PD) over the past decades to involve the social in the design and development process, After discussing this prior art, we want to conclude this paragraph with a short discussion on the process of continuous integration. This process, with origins (in the Informatics and Engineering, also copes with issues that are raised whencollaboratively building software systems.

The SCOT theory explains why social context needs to be into account in IT innovation processes. In line with the SCOT perspective it becomes clear that a pervasive technology reflects different problem definitions and concerns. One has to assess the power relations; norms and values at that moment and place. A crucial idea in SCOT theory is that the outcome of a technical solution is the result of a path of choices: the solution could have been totally different, since in the development process a lot of sidetracks have been taken into consideration and abandoned. A current successful technology is a crystallization of choices that work, not the symbol of the most ultimate best solution. One best solution does not exist. For more in-depth understanding of SCOT we refer to work of e.g. Bijker (1997) and Rip et al_(1995).

Limonard and Koning (2005) rephrase SCOT into a core tension between i) the role and acceptance of a technology, which is primarily determined by social forces, so looking at søcial context is key (i.e. the 'social shaping' of technology), and ii) the context of use (re)shapes the meaning of the technology, and how that evolves is rather unpredictable (i.e. the 'mutual shaping' of technology). Following the aubors' own expertise in pre-competitive ICT development projects, they acknowledge the need for awareness of this tension and describe on an abstract level the process of critical examination one has to follow as part of the whole R\&D process (Limonard and Konings, p 169). We think the 'innovation binder approach' can be seen as an operationalization of Limonard and Koning's more generic strategy. They distinguish three dilemmas during pre-competitive ICT development projects. : $(i)$ the starting point in configuring future use of ICT technology (the current social-technical context of use versus the future use of technology in context); (ii) the way of involving users (pro-active versus reactive); and (iii) the dilemma of the organization of interdisciplinary cooperation (the laboratory versus the development arena). Sequencing the different aspects of the dilem- 
mas throughout the project is suggested as a solution. We will show in the description of the 'innovation binder' approach how this was achieved, and where and why we took another road than suggested by Limonard and Koning.

The investment in interdisciplinary work is driven by the need to join methods of different disciplines to answer a complex question. Van Bemmel (2008) states that this is certainly the case when healthcare meets informatics. Stewart and Claeys (2009, p.2) wrapped up several difficulties from literature: epistemological differences, identity, membership conflicts and cultural capital, terminological misalignment, resistance to input from other disciplines, power issues, structural biases and management failures. To stimulate interdisciplinarity, one should take these issues into account. From their own experiences involving research with "users' Stewart and Claeys advise $(i)$ to invite everyone in the team to êngage with users, not only social scientist or user researchers, (ii) to stimulate each team member to go beyond their own world view, and enable to have a conmon experience, (iii) to involve the team in the analysis ( $i v$ ) to be opento the disciplines, interpretations and methods of other project partners (p18).

The involvement of social scientists, or experts in HCI and PD, in the development process of pervasive health systems is not new. Pagliari (2007) for example described a hybrid model for interdisciplinary research in medical informatics where the goal is not only to share information, but actively design and evaluate and thus reach technologies that are "truly user-informed, fit for context, high quality and of demonstrated value"(p.1). However, this model emphasises evaluation and excludes conceptualization, neither does scenarios play an important role as a boundary object. We think that the ambiguity in the story can indeed function very well as boundary object in the original way defined by Star (2010): an arrangement of collaboration without prior consensus between different groups.

We are not the first to see lot of possibilities in the scenario as design tool (e.g. Johansson \& Arvola,2007), nor are we unique in using scenarios as the core of involving the socialin software design. There is a well-documented tradition of different uses of scenarios and personas (e.g. Muller 2002, Karasti 2002, Pruit \& Adlin 2006), as well as an instrument to involve user involvement from evaluation to co-design((Bødker 2000). Scenarios differ from use cases, which are more oriented at users tasks and specific computers functions. Scenarios are rooted in specific situations, in a certain context. They are based on knowledge on how things are done. They describe what is done, where, by who, when and by what means in what way (Bødker \& Christiansen 1994). In contrast, use cases are generic, they describe the possibilities a technology offers to an end user, but there is no insight in the use context or the needs or preferences of the end user. As such, scenarios are better tools to integrate both a technical and social perspective than use cases. Different types of scenarios are made depending on the goal they must serve. They differ e.g. in openness, on depicting typical or critical situations, showing the extreme positive and extreme negative consequences (Bødker 2000). Scenarios play a big role in the 'innovation binder' approach, and they are used in different ways throughout the process: $(i)$ scenarios that are hypothetical or scenarios that are 
grounded in research on and with users; (ii) scenarios that are oriented at the current or scenarios oriented at future practices (current practice and future practice scenario); (iii) scenarios that assume the technology works flawless (sunny day) or that include technology failure (cloudy weather) ${ }^{1}$; (iv) scenario depicting a desired system ('desired scenario') or a system representing your worst nightmare ('horror scenario') ${ }^{2}$. Because we do not want to be too overwhelming about variation in scenario options, we distinct in the Innovation Binder between $(i)$ the hypothetical and the grounded dimension, and (ii) the current and the future dimension.

In line with Muller (2002, p11), the 'innovation binder' approach serves to create a hybrid space where technology developers/researchers come together with the end-users representatives/researchers. Therefore, it is important to integrate methods that are understandable for those, non-social scientist dealing with the typical problems of making complex software systems in an interdisciplinary team. Continuous integration (CI) is one of them. It is a method adrocated by Martin Fowler since $1999^{3}$ in order to improve quality and delivery time of software developed in co-development teams. In our projects, these co-development teams often originate from different organizations and geographical locations (researchers, private companies, subcontractors) so this makes integration problems with the software building blocks even more likely. A required first step in CI is maintaining a common software code repository, supporting revision control. Having the software developers commit to these common repository on a very frequent base, contributing to an agreed mainline is essential. Automated builds and testing resolves the problems of integration testing normally done at wider time intervals. In practice, the CI process can only be successful if an 'integration manager' commits explicitly as being the problem owner of the CI process. In our interdisciplinary teams, the CI process needs also to interact with the user research process. In our exploratory R\&D projects there remains a high number of potential variables, both at the levelofthe technology and the end user. As such, the standard CI methodology cân only be part of the solution for our type of interdisciplinary projects. Therefore, throughout the pervasive health projects that we worked on in recent years, a new approach was developed.

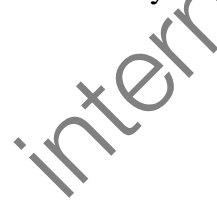

\footnotetext{
${ }^{1}$ Inspiration from the distinction in use cases http://www.gatherspace.com/static/use_case_example.html\#3

2 This last type is also called by Bødker (2000, p64) minus scenarios.

3 http://www.martinfowler.com/articles/continuousIntegration.html
} 


\section{Situating the context of use in which the approach was developed: when to use the innovation binder}

The exemplary projects presented in this chapter are all part of a demand driven research projects, partly funded by the participating companies and partly by the Flemish Government through the interuniversity and interdisciplinary knowledge center iMinds (www.iMinds.be). Healthcare is one of the important application domains since the conception of iMinds in 2004. The projects are pre-competitive and have a two years time-span. A project assembles different expertise to work towards a common research goal, resulting in reports and proof-of-concepts. In our examples, we will refer to experiences from several projects. These include the finished project ACCIO (2010-2012, developing a contextual nurse call system making use of ontologies and sensor data, Ongenae et al 2012) and TransEcare (2007-2009, creating transparant ICT platforms for eCare); and to current experiences in the O'CareCloudS project (2012-2014, developing) a contextual information sharing system between caregivers), Fallrisk (2013-2014, on contextual fall risk prevention and detection using sensor information) and the AAL project Care4Balance (2013-2015, on dashboard applications for elderly to coordinate care provisioning).

The 'innovation binder' approach in its current form originated from these projects. The approach tries to deal with a number of challenges that project partners were typical. A number of these are listed below.

In the first iMinds health projects, we gradually succeeded in creating more attention for user needs in IT innoyation in health (De Rouck et al. 2008). Interactive reflective discussions with technology developers are part of this method. However, many user researchers still had the feeling the results of their research were underutilized in the cevelopment process (e.g. Limonard \& Koning, 2005) and felt they were unable to substantially influence the conceptualization and implementation of the technology.

Another tensiop results from the difference in time spans the project partners are working on. Technical university researchers aim for a leap from the current state of the art of technical solutions, while the involved companies and care organizations are looking for mid-term reachable solutions to be valorized. Continuous integration tools are only helping to keep track of the connection and iterations of the technical components. But these tools do not help to make choices.

The user researchers typically struggled with having to research the possibilities the technology under development offers, without being able to give targeted users an experience of the future solution. Also, technical partners often considered input from social researchers as helpful, but also as delaying the process.

We developed thus the 'innovation binder' approach to guide us to make those choices collaborative, see our interdependencies and document systematically to stimulate reflection. Although it grew out our cases in pervasive health technology, we think the approach also could be useful in other domains. 


\section{How the innovation binder approach works today}

In the next paragraphs we discuss in detail the different steps and aspects of how we currently use the innovation binder (fig 1.).

Roughly, we distinguish four types of actors: $(i)$ social science/HCI researchers, (ii) engineering or computer science researchers, (iii) people working in (R\&D departments) of private companies, and (iv) people working in (health)care organizations. These people collaborate along two types of streams: the social stream and the technical stream. Identifying oneself with one of the actors was never problematic in our projects. The different actors, their activities and expertise come together, being continuously stimulated to make choices bassed on the newly gained knowledge by the different partners. The leader of the proeess is fixed. In our cases, the project leader takes up this role, or a dedicatedperson who got extra effort on the planned innovation binder tasks.

As in most creativity processes, we start with a divergence phase and move subsequently to a convergence phase (Isaksen et al., 2011). The divergence phase is called the 'concept development'; the convergence hase is called the 'proof-ofconcept development'. During the concept development, we want to create a space for creativity by different research activities binding them together by one jointly created story. In the proof-of-concept development phase, the goal is to converge with the remaining R\&D activities towards a stable proof-of-concept that demonstrates the added value. We will now deseribe the different steps, illustrated with some concrete examples.

\section{Concept development phase: guided explorations for a vision of a future pervasive health system}

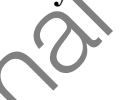

In the concept development phase we foresee four steps: (1) introducing the method, (2) making expectations explicit, (3) documenting current practices and technologieal roadmaps, and (4) co-creation. The three latter steps all result in a different kind of scenario. For each step we describe the objectives, the participants, the sub steps and their outcomes, examples and reflections. 
Step 1: Embedding the innovation binder approach in proposal and introducing at project kick-off

\section{Objectives}

- Structurally embed the innovation binder approach in the project, with sufficient time and effort of all partners on the task.

- Create a buy-in of all partners by explaining the goals and trajectory of the approach.

\section{Participants/lead}

All partners are involved.

Step 1.1 Writing dedicated tasks in the proposal

Integrate the different steps in project plan, for example in a proposal to apply for grant money. It is important to dedicate sufficient time for the different steps throughout the total timespan of the project.

Step 1.2. Introducing approach at the kick-off of the project

When the project starts, it is useful to spend some extra time explaining the 'innovation binder' goals to all project participants, and what the advantages and different steps are.

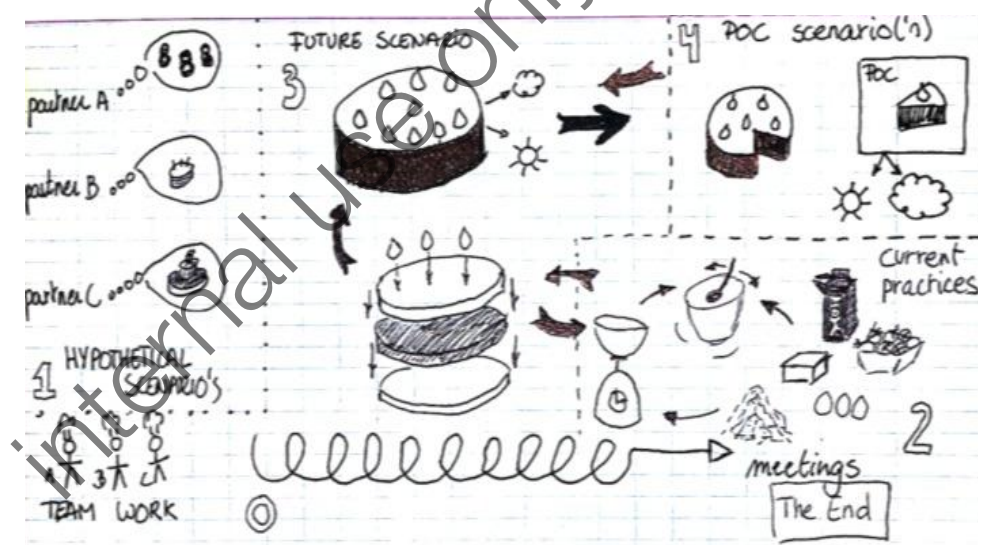

Fig. 2 'Baking a cake' metaphor to explain goal of approach 


\section{Example}

To integrate the 'Innovation Binder' into a proposal, the steps of the Concept Development phase (step 1-4) are located in the explorative work package defined as "Requirement Analysis" or "Domain Analysis", and the Proofof-Concept development steps (step 5 -7)) of the 'Innovation Binder' are defined as tasks within the "Evaluation", "Demonstrator" or "Proof-of-Concept" work package.

To explain the innovation binder goals and approach to the participants, we used in O'CareCloudS, Care4Balance and Fallrisk the 'cake baking' metaphor (as illustrated in figure 2). We deliberately opted for recognizable but unfamiliar comparison, without any relation to health or the technology in scope. Thus, attention can be triggered, in an equal and humoristic way. The approach is compared with the practice of baking a cake with different baking spediahsts (bakers, oven specialists, etc.) who represent the partners. Each of the partners has their own ultimate dream cake in mind. First, we make these different dream cakes explicit by creating for each partner their hypothetieal scenario. Secondly, we look at the current practices of making cakes, and maybe even broader practices surrounding cooking in general. We make a synthesis of these practices, by describing them in a current pracfice scenario. Thirdly, by combining the insights on current practices with the ambitions and expectations of all partners we create a grounded future scenario of our ideal cake. In this step of the process, it is important to come up with grounded scenarios on a sunny day when everything in our cake báking process runs smoothly (sunny day scenarios), but also to think about (eldudy weather scenarios when the cake baking process have technical problens. Finally, in the fourth step we decide on which piece to make, since the total cake is too big to finish within the project time. We select the piece (big, small, a lot of cream or more fruit) considering the current needs, and the expectations/ ambitions (proof of concept scenario). Although the four steps are consecutive, there is also a lot of going back and forth between the steps, and regular meetings of all with their own skills and specialties facilitate this.

\section{Reflections}

This step is not in the learning cycle of Limonard and Koning (2005), but it is essential to stimulate iteration between field and lab approach of interdisciplinary cooperation they put forward as necessary.

It is crucial to give room to the participants to discuss and doubt the approach. Next to the general added value (supra, intro), for each actor this added value is different:

(i) The work of the social science researchers is easier translated into technical choices, and involvement in technical related choices without deep technical 
knowledge is facilitated. When well documented, it is easier to show the added value of their work.

(ii) For the engineering and computer science researchers the added value lies in making social relevant technological choices and keeping the balance between research and implementation efforts.

(iii) The participants from private companies developing new pervasive health technologies can keep a close grip of the fit between their technological roadmap and the research done. As such, the approach will facilitate the valorization of the project results for their company.

(iv) Finally, the participants from the care organizations can relate in more everyday language to the technology under development and be more involved in the reflection on it the impact of the technology on care providers and receivers.

Step 2: making expectations explicit towards a hypothetical scenario

\section{Objectives}

- Make ambitions, goals and expectations of each partner explicit for the other partners.

- Create hypothetical scenario(s) based on these expectations to facilitate discussion.

\section{Participants/lead}

At least one representative per partner should participate. The social science researchers take the lead, because they are more trained in making a narrative out of different points of views

\section{Step 2.1. Elicit expectations and ambitions}

All project participants bring their own background and motivation to the project, nex to the organization's motivations. The proposal holds clues on each partner s expectation and ambition. But due to a time gap between proposal and stârt of the project, changes happen. To understand the view on challenges, technologies to be used and target group, different methods for elicitations are possible: analysis of the proposal, a questionnaire, a hands-on workshop on the overarching project topic, etc. For inspiration on how to organize this elicitation, we refer to methods like Territory Maps and Stakeholder Maps (Martin \& Hanington, 2012, p. 80, p. 85). 
Step 2.2. Joint meeting discussing expectations and ambitions

Similarities and differences are mapped and discussed. If a workshop type of approach is used, the workshop needs some preparation as well. Either way, creating mutual understanding needs a social process like a meeting.

\section{Step 2.3. Translate and synthesize in hypothetical scenario(s)}

The hypothetical scenarios (current and future practice) are based on these discussions. The number of scenarios depends on the variation in expectations amongst the project partners. In the next steps these scenarios are challenged and reflected upon until the end (compare start with final project results). The hypothetical scenarios also help to make explicit what the project partners do not know yet and where research is required. 


\section{Example}

We experimented with different ways to elicit expectations and ambitions: examining from the proposal, a questionnaire and a hands-on workshop.

\section{1) examining the proposal}

In the TransEcare project, two social researchers made an analysis of the different sub-themes of independent living that were part of the proposal, and which partners planned to work on these themes. This anatysis was represented in a table, which we discussed during several joint meetings. We added other aspects of interest not that clear from the proposal. Later in the project, these tables were re-used for the prioritization of POC integration.

\section{2) open questionnaire}

In the Fallrisk project, a use case was included in the proposal, describing of the current situation of the prevention and detection system under development. Using an online questionnaire with open questions, we asked the partners to describe the actors, practices and technologies as they envisioned for the project, and to provide visuals to illustrate their vision of the future they want to support with the new system (Elprama et al. 2013).

3) hands-on workshop

In the ACCIO project, we involved all project partners in an initial workshop. One goal of the ACCIO project was to develop a new way to co-create knowledge models in the care domain. The workshop explained the basies and hurdles of knowledge model engineering by performing anstep-by-step exercise, actively involving all the participants. This resulted in a discussion on the opportunities we saw for this technology in our project (Ongenae, 2011). In comparison to the use of a questionnaire, this was experienced to be a more hands on way of explaining the process.

A hypothetical scenario is based on these expectations of the project partners. Only a sunny day version is made. In Fallrisk, two hypothetical scenarios were written: a scenario on the hypothetical future, and a scenario on the assumed current practices. Thus, also assumptions and (lack of) knowledge on the current practices can be shared. A short example of a scene from the first version of a hypothetical scenario is shown in Table 1 . 
Table. 1: First iteration on the hypothetical scenario, mapping questions.

\begin{tabular}{|c|c|c|}
\hline $\begin{array}{c}\text { Scenario B } \\
\text { Installation and explanation } \\
\text { of system }\end{array}$ & & \\
\hline Current situation & Future situation & Comments \\
\hline $\begin{array}{l}\text { Last week Marie walked to her } \\
\text { sofa to watch some TV, but then } \\
\text { trips over her carpet }\end{array}$ & Idem & \\
\hline $\begin{array}{l}\text { Tom discusses his concerns with } \\
\text { his mother, Marie. Together they } \\
\text { agree to request a PAS system }\end{array}$ & Idem & \\
\hline $\begin{array}{l}\text { Tom contacted a home care } \\
\text { organization to inform about } \\
\text { the PAS and he asked to install } \\
\text { the system }\end{array}$ & $\begin{array}{l}\text { Tom contacted a home care } \\
\text { organization to inform about } \\
\text { the Fallrisk system and he } \\
\text { asked to install the system }\end{array}$ & $\begin{array}{l}\text { Question: in future scenario: } \\
\text { which kind of organization } \\
\text { would provide support? Also } \\
\text { home care grganization? Insurer? }\end{array}$ \\
\hline A couple days later... & & \\
\hline $\begin{array}{l}\text { A couple days later, nurse Celine } \\
\text { comes to install the PAS system } \\
\text { and she also explains how it } \\
\text { works to Marie and to the family } \\
\text { care-giver(s) present }\end{array}$ & $\begin{array}{l}\text { A couple days later, nurse } \\
\text { Celine comes to install the } \\
\text { Fallrisk system for Marie } \\
\text { and she also explains how it } \\
\text { works to Marie and to the } \\
\text { family, caregiyer(s) present }\end{array}$ & $\begin{array}{l}\text { Question: are the children } \\
\text { typically present in this situation? } \\
\text { Reaction care organisation: } \\
\text { ideal at least one formal caregiv- } \\
\text { er present and he/she makes sure } \\
\text { that the informal caregiver un- } \\
\text { derstand system }\end{array}$ \\
\hline $\begin{array}{l}\text { The PAS system comes with a } \\
\text { small button that Marie needs } \\
\text { to carry with her. The button } \\
\text { can be carried as a necklace or } \\
\text { as a bracelet. Marie can also } \\
\text { clip the button to her bra, } \\
\text { so it's not visible for others } \\
\text {... }\end{array}$ & $\begin{array}{l}\text { The Fallrisksystem can detect } \\
\text { falls with cameras and sensors } \\
\text { inthe house and worn by } \\
\text { Marie (eg smart phone). } \\
\text { It not only detect when she } \\
\text { falls, but also warn Marie } \\
\text { and her caregivers when her } \\
\text { risk of falling increases after } \\
\text { measuring over some days }\end{array}$ & $\begin{array}{l}\text { Question: in the future system: } \\
\text { the active button is not removed? } \\
\text { Answer social scientist: prefer to } \\
\text { keep it optionally in to give } \\
\text { Marie the feeling of control }\end{array}$ \\
\hline
\end{tabular}

\section{Reflections}

Step 2 offers an opportunity to get to know the people and organizations involved in the project more closely. This step helps to understand partners' dependencies and drivers to invest time in a certain aspect of the project, and where to find a better fit in interests. It is important that all partners realize there is no need to wait for the others to finish: both technical and social streams can start (mutual shaping). 
In this phase of the project, the 'innovation binder' approach serves to build a foundation for interdisciplinary work in addition to the proposed learning cycle of Limonard and Koning (2005).

Step 3 Documenting current practices and technological roadmaps: validating current practice scenario and creating future practice scenario

\section{Objectives}

- 'Ground' the hypothetical scenario by studying the current practices, the care domain, the technological opportunities and their building blocks.

- Focus on current practices with and without technologies, while reflecting on the assumptions for the future change.

\section{Participants/lead}

In this step, the activities are diverse. There is a focus on the contributions from the own discipline, but mixed teams are also formed.

Step 3.1 Researching current practices and freedom to operatel technological roadmaps

Different research activities are started: deepening state of the art literature, studying current user practices and examining technological roadmaps (more detail see e.g., Bleumers et al., 2011). The hypothetical current practice and future scenario can be used in this phase-to probe for feedback from users. The scenario is thus challenged by reflections by potential future users. User roles are redefined and thick personas created (Jacobs et al. 2008).

\section{Step 3.2. Intermediate joint meetings}

All these inquiries finally end in reports and artifacts, but in order to create a dialectic interaction between the social and technical stream, meetings are required to enable work on intermediate results (mutual shaping). This can be facilitated by preparation of meetings by different partners depending on the main topics under discussion. These meetings can stimulate co-ownership of the output. During the process hypothetical scenarios are gradually turned into grounded scenarios of current practice and future practices with the pervasive health system. This 'future scenario' is tied to the proposed architecture. In this iterative process, spread over several meetings, the future scenario matures by the inclusion of results of the different research activities. At first, it stays focused on the sunny day version. While maturing attention to anticipate the cloudy weather version, when the technology does hamper, should increase. 
This is also the moment when designing a generic architecture of the pervasive health solution is helpful. This generic architecture links the envisioned technical components and details the communication flow. The detailed architectural work can be done later.

Creating an architecture is a technical task, but by making use of TechCards (Ocnarescu, 2010) it is possible to start the integration work in an interdisciplinary way as well, as such building bridges between partners and disciplines. These TechCards (see example section) describe in a generic way the technical components that the different partners are working on. In this way, an overview of the components and which components need to work together is created. Also, awareness is created about the components and links that may be missing. They are object of discussion during meetings. In contrast to the method where a "common glossary" is made for the project, e.g., in the form of a wiki, to facilitate interdisciplinary communication, this tool is more hands on and feels less like writing a burdensome dictionary.

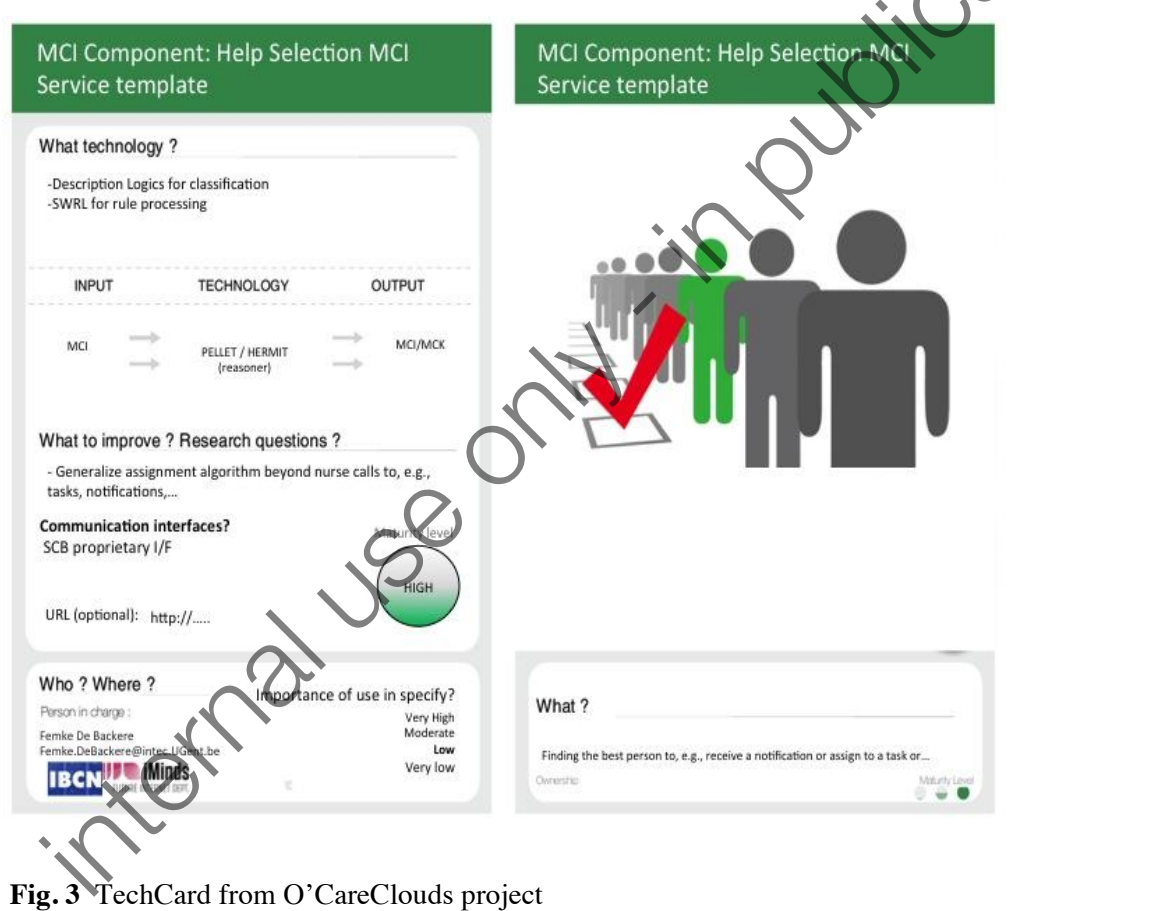

Fig. 3 TechCard from O'CareClouds project 


\section{Example}

To illustrate how the different research activities interact, we present research activities from the project OCareClouds. One of the first research activities of the social scientists in the project was to perform a domain analysis on the care diary currently used to coordinate the care activities between formal and informal caregivers. This was done by means of a literature study on caregiving processes, and a series of expert interviews with different people of the care organizations involved. Concurrently, a mixed team of social and technical researchers took part in a contextual inquiry of the current formal care delivery process of the involved care organizations. In parallel, a first design of the architecture was made, making use of the technical components as mentioned in the project proposal.

In addition, and inspired by our colleagues Claeys L. and Criel J. who tested the approach out in other projects, we implemented the TechCard approach in both O'CareCloudS and Care4Balance. Each partner involved in the development of technical components had to describe their technical components in a template of the TechCard (see for an example figure 3). In the follow-up joint meeting, all partners present their component(s), and the right-evel of abstraction is determined. Some changes or new cards are made afterthis meeting. The TechCards are also mapped on the different functionahties already determined in the current iteration of the scenario. This approach enables the different partners to reflect on the responsibilities regarding the different components. It also helps to discover missed communication links and components, i.e., a missing functionality and to reflect on the complexity, scalability, usability and generic applicability of the different components.

For example, in OCareCloudS the overview of the cards triggered a new view on how to design the back-end architecture. The back-end components reason on integrated patient data to trigger alerts to the caregivers. Originally, these components were split so each covers a complete use case domain, e.g., alerts about the physical healthcare state of the patient. The TechCard exercise made aware this was not scalable nor user-friendly enough for the future software developers and noteasily adaptable to future scenarios. A 'template approach' of different functionalities, e.g., a monitoring template, was the new solution. A back-end component is then built as an instantiation of such a template, e.g., a blood pressure monitoring component. As such, very scalable and small components are achieved with a very specific purpose, while userfriendlines for the software developers is assured by offering the different templates.

In both projects the cards engaged the non-technical partners more in the technical components, but it also spurred technical groups to collaborate more. The TechCards help to make promises less vague. This improves the quality of planning towards the proof of concept. 


\section{Reflections}

State of the art knowledge is necessary to formulate the research plan. But to update and collect deeper available knowledge, it is advisable to foresee some state of the art work here both from the social and technical side. The formulation of a scenario of current practices is something we recently added to the process, in order to document the evolution of the project. Also, the TechCards approach is a recent addition to the innovation binder process, which resulted from the need for a tool to facilitate communication amongst the technical partners, and between the technical and non-technical partners.

In this step the recurrent dedicated 'innovation binder' meetings are still at a low frequency. They are integrated in other general status meetings. A stepwise discussion of the scenario in a dedicated separate meeting is prepared by assigning all partners to comment on the scenarios. Depending on the skills of each partner, the comments on the scenario will be more technical or social in nature, stimulating again the dialectical interaction and mutual shaping.

During this step there is a tension between divergence and convergence. Often at the social research side, there is the fear to fix choices too early, while at the technical development side stability is searched to be able to develop in detail. It is important to start the architecture and TechCards discussion at this stage, to limit the urge of the technical partners to rush the stabilization of the scenario. Based on early versions of the scenario, it is already possible to identify the high-level components and the communication links needed, This ensures that some of the pure technical discussions, e.g., communication formats, generic interfaces, used technology, are tackled early on in the project, while the social scientists have more time to ground the scenarios. Moreover, this ensures that later technical discussions can focus on the functionalities detailed in the scenarios, i.e., focus on what the components should communicate and perform, instead of on the pure technical integration issues, i.e., evatuate whether the components are able to communicate and which technology is regured for this.

Step 3 is in line with the activities described in the learning process by Limonard and Koning (2005) under the social shaping view: present context of use, pre and pro-active user Involvement and use the research results to steer the different kinds of expertise.

(

Step 4 Co-creation with users of the concept \& design and development of the concept: towards an optimal ideal future scenario. 


\section{Objectives}

- Organize co-creation activities to develop the concept and to stimulate technical choices.

Ensure that the future scenario reaches full maturity.

\section{Participants/lead}

The social research partners lead the co-creation with users. The care organizations are in the lead to recruit participants for the co-creation activities. The technical partners are in the lead of the technical choice process. Mixed teams are formed for the co-creation sessions.

Step 4.1 Co-creation activities and development technical component

Once the basic concept is made more concrete by the available teehnical components, we organize co-creation activities with the target usergroup(s). There is a wide variety of available techniques: story boarding, role-playjng, paper mock up experiences, guided brainstorms, etc. One could of course start with these activities in a less technical influenced way once the context of use and user group are known (Step 3).

The first common agreed upon version of the future scenario could be integrated in this co-creation exercise. It can be used as a starting point, or as a way to offer a new point of reference, elicit openness towards the characteristics of the pervasive technology. The results of these activities are then translated into an "update" of the future scenario where the technology works flawless (sunny day scenario).

Step 4.2. Joint meetings integrating the results and making socio-technical choices

Open options and current choices are discussed in-group to evolve towards the realization of the "updated" future scenario. We limited the time of these meetings to a maximum of 3 hours per session, so each partner knows preparation is needed and decisions should be reached at a certain pace. Depending on the topic, the composition of the team (number and background of participants) that meets can differ. But in principle, all meetings are open for all project members.

The goal of the meeting is to match the user opportunities and needs with the technical developments. A lot of time is spent on mapping the different technical components on the scenarios, helping to determine the priority of each service and components, as well as identifying the ones that are missing. The TechCards made earlier are used to facilitate this exercise. The future scenario is split into scenes of actions and the TechCards are mapped on then. In combination with the level of maturity the priority of the further development of each component can be thus determined. 


\section{Example}

During the ACCIO project we experimented with different types of cocreation workshops during the whole trajectory. A detailed description and comparison of the workshop types can be retrieved in Ongenae et al. (2011 \& 2012). For example, the first one was a role playing workshop during which we let different stakeholders from the care field play scenes from the future scenario, offering information on both current practices, used concepts for the ontology and the envisioned future use of sensors in a ward environment.

Concurrently with the mixed team activities, the technical partners deyeloped so called 'dummy' components and integrate them to evaluate whether the proposed architecture and communication flow is feasible and whether the proposed technologies are sufficient to reach the goals of the project In the OCareCloudS project this integration was done with sending dummydata from one component to the other, during the ACCIO project implementing a very simple sub scene of the scenario was chosen for technical evaluation purposes. In this way continuous integration is started: stimulating the decision on the kind of data and enabling each partner to focus again on their own component.

Maturing the future scenario implies adding details on interfaces, measures for making a secure system, type of data input and output. In this way the scenarios also carry the implicit technical requirements of the new pervasive system. For example, the amount of data generated, the type of data that should be transferred between the different components to be able to transform the input to the output, where the data will be stored. Based on these requirements, technical solutions can be selected, aking into account the motivations of the partners as mapped in Step 1. For example, when one of the goals of a partner is to research the feasibility of integration of a new TV platform, it is unlikely not to use it.

Reflections

The 'innovation binder' approach appears to be more important in cases where the technical work is not that much related to the end user interaction. Without such a tool, the engagement of the technical group with non-technical research insights would remain low.

At this point in the process there are three types of scenarios: the starting hypothetical scenarios, the finished scenarios synthesizing the current practices, and rather mature future practice scenarios. Each of them is helpful to reflect on the process, as well as a tool to let new participants enter the project, as often personnel changes happen during the project time of 2 years.

In step 4 we move away from the present socio-technical context of use and focus on future use of the technology, enabling reactive user involvement which aims for visions/ambitions instead of a orientation on current problems (Limonard 
\& Koning, 2005, p175). Step 4 can overlap and interacts with step 3. Consequently, the 'innovation binder' stimulates to look concurrently at both the current use context (step 3 ) and the future use context (step $4 \& 5$ ), one of the dilemmas raised by Limonard and Konings (2005).

\section{Proof of concept development phase: towards an evaluated proof of concept} with value for business and society"

The next steps describe what we have called "the convergence phase" This phase aims to bring the R\&D activities to a stable proof-of-concept that demonstrates the added value of the project activities. The timing to converge is most often dictated by the project rhythm itself. It is thus a pragmatic choice. In our project rhythm of 2 years, we see the one-year project milestone as a good timing to go to the converging phase. In this phase the intensity of the joint meetings is also increased. We strive towards a rhythm of biweekly meetings.

In the proof of concept development phase, we canidentify 3 steps: 1) refinement of the concept and development of proof of concept scenarios (step 6), 2) realization of the proof of concept(s) and evaluation with users (step 6) and 3) project ending and knowledge transfer towards alorization and further research (step 7).

Step 5. Refinement of concept and developing the proof of concept scenario

\section{Objectives}

- Improve the concept detailing.

- Iterative user evaluation with the material at hand: paper, mock up or in lab working prototype.

- Maintain the continuous integration: update the components, retest the internal communication.

Test the technical requirements (e.g., scalability, performance and responsiveness).

- Select the pieces of the future practice scenario, to create a proof of concept scenario. List the development work and the evaluation options.

\section{Participants/lead}

The technical partners tend to take the lead, because of the growing focus on continuous integration and the proof of concept. 
Step 5.1. Choosing parts of the future scenario to be developed as proof of concept

Multiple factors influence the selection of pieces. Two main points of attention are usually taken into account: $(i)$ the proof of concept needs to illustrate innovativeness of the pervasive health system under development, and (ii) the proof of concept needs to demonstrate the added value for the different end users. The fit between those two aspects leaves some opportunities to create added value unresolved. To aid this process of choosing pieces of the future scenario, the mapping exercise on the scenario (previously done with the TechCards) can be repeated here: now the different scenes of the scenario can be rated on different aspects that are relevant for the development of the proof of concept (e.g., innovativeness, maturity, desirability, effort needed to develop, partner ambitions, etc.).

\section{Step 5.2. Creating proof of concept scenarios}

The difference between the proof of concept and the future scenario is that in the proof of concept scenario the future scenario is being 'translated' to the time, technical components and skills available in the project. As a result, some parts will be done with a suboptimal, but working solution. Interfaces and devices are also more fixed in detail in these scenarios. Attention for the possible flaws in the system should be explored, and are best documented in making alternative cloudy weather scenarios.

Step 5.3. Additional research to ground prof of concept scenario where needed

The future scenario is still on a quiet abstract level of the description of practices. To come to the level of real implementations for the proof of concept, some abstract ideas should be studied in more detail. In that way they become less based on guesswork, but are further grounded in knowledge about the care domain.

\section{Reflections}

The joint meetings are time intensive and therefore best planned in advance. For some smaller organizations, it is sometimes difficult to make this time investment. Especially for care organizations, continued presence could be hard if there is nofunding for this work. The organization and the flow of the meetings also dependion the size of the group: a larger team offers more diversity in perspective, but a smaller team is more dynamic. In a larger team it is also difficult to keep everyone engaged and to determine whether everybody understands and acts his or her role in the process.

Precisely in this step, we fully embrace the mutual shaping aspects of the dilemmas described by Limonard and Konings (2005): the future context of use is the core focus, the user is involved in validation of the ideas (reactive user involvement) and testing and modifying is in the interdisciplinary cooperation mode. 
Step 6: Realization of the proof of concept and evaluating it with users

\section{Objectives}

- Show one or more proof of concepts.

- Learn iteratively from in-between evaluations of the proof of concepts

\section{Participants /lead}

The task is lead by technical partners, but in close interaction with the social scientists and the care organizations providing the evaluation strategy and recruitment.

\section{Step 6.1 Integrating towards a working proof of concept}

In this step, continuous integration is at its highest intensity: having a central repository and testing over and over again. Testing needs to clarify how robust the proof of concept is, also if it can be set up outside the lab, and how many pieces of the test setup are feasible to make. The team works towards the demonstration moment where it tries to provide an evaluation setup as close as possible in the envisioned context of use with the targeted users. To reach this goal we advise a stepwise approach going out the lab towards the field, as described in Ackaert et al. (2009).

\section{Step 6.2 Evaluating the proof of concept with different users}

The proof of concept scenario is also helpful to evaluate the proof of concept itself with users. In our experience, most of the time the pervasive health proof of concepts are not robust enough to go 'into the wild'. In order to obtain valuable user feedback, different solutions are available. For instance, the team can organize a role-playworkshop revolving around the proof of concept, supplied with mock-ups of those features that have not yet been implemented. As such, it is possible to create an improved second proof of concept that is based on significant user tests (Ongenae, 2012).

Step 6.3 Iterating towards new proof of concept

During the selection of elements to include in the proof of concept, the features

\section{Example}

In the ACCIO project, one of the goals was to show the relevance and feasibility of working with ontologies in the back end. This steered the decision to pick those scenes in the future scenario where the added value of this technology could be shown both from a user and technical perspective, illustrating a balanced use of computer reasoning and human intervention in the process (Ongenae, 2012). In the Care4Balance project, one of the main drivers is having a demonstrator that is able to show the reciprocity between caregiver and care receiver, as well as using a new interface. These focal points guide the selection process for the proof of concept scenario.

To spur the continuous integration we had a good experience in the Care4Balance project with a co-programming one-day workshop where we looked into making a proof of concept with the components at hand for one day. This workshop was guided by the information of the TechCards and a technical partner in charge of the central platform guided the work. Short sprints are done on each component, after which each sub team explained to the rest with a mini demo what is achieved in the previous time frame. 
that need most development time are often postponed towards a next iteration of the proof of concept. However, it is also essential to foresee effort to implement the user feedback on the first version, so an improved version both on the social and technical level can be produced.

These three steps can be repeated if the project time allows it.

\section{Examples}

In step 6, the added value of the continuous integration effort becomes most clear. When using the 'innovation binder' approach, the technical researchers keep using the proof of concept scenarios to guide the planning, next to the preferences and skills of the developers. Technical meetings are held frequently, however, it can be recommended to have a social researcher following them as well. This person can track the changes driven from technicalconcerns, as well as changes in functionality that could be shown during the evaluations. As explained before, for these functionalities that have not yet been implemented, a mock-up needs to be the designed for the evaluation. During the evaluations, it is essential that a technical developer/researcher is present to support the user researchers when the system gets quirky. When doing user tests outside a lab setting and into the field, continuous technical support should also be foreseen at close distance (Ackaert et al., 2009).

\section{Reflections}

The proof of concept scenario has to remain rather stable, because of the interdependency of the components However, as a result of this, developers might tend to use the proof of concept scenario as a shield, arguing against any modification of the technology under development because "it is not mentioned in the scenario". The consequences should be discussed, and if the disruption is too high one can add this change to an update of the ideal future scenario and maybe integrate it during the next proof of concept iteration. Going back to the other options left out in the proof of concept scenario is also simple, since they are documented. Alternativechoices are consequently easier to make in a next iteration.

This is a continuation of giving attention to the mutual shaping cluster of the dilemmas (Limonard and Konings, 2005) started in step 5. In step 6, we try to link back to the first step by bringing the proof of concept as close as possible to the present context of use. Acknowledging that only partial knowledge is gathered due to the unpredictability of the innovative use when the pervasive solution is appropriated in everyday practices. 
Step 7: Ending the project and transferring knowledge towards valorization and new research

\section{Objectives}

- Stimulate valorization and transfer the outcomes of the project.

- Reflect on the total trajectory and the lessons learned from the interdisciplinary teamwork.

- Create grounded new research trajectories.

\section{Participants/lead}

Every partner should be involved, while the lead of this task is mostly with the project leader.

Step 7.1. Reflecting on choices, lessons learned and starting to re-diverge

In this step, the final update of the future scenario can be made. The reflection on the projects' process and the outcome, the demonstration of user centered designed pervasive health system can be made by comparing the hypothetical future scenario with the final future scenario. Reflections on the gap between this scenario and the demonstrator can be helpful to determine the next steps and alternative choices to make and test (re-divergence).

Step 7.2 Final reporting of project results and transferring the knowledge

This is the bread and butter of every R\&D project, but by using the innovation binder process, the differentseenarios and documentation of the process can help to show the insights and innovations in a more comprehensible way to a diverse public (funders, potential elient care organizations, potential investors for further development).

\section{Examples}

At the end of the ACCIO project, we held a closing event presenting the results and linking them to the broader societal debate. At this event, we illustrated the subject of a follow-up project on the use of ontologies in the home care situation by making use of an adapted format of one of the workshops we did with end users during the ACCIO project. The proof of concept scenario in ACCIO was used to contextualize the results of the technical demonstrator. In addition, we organized a final internal ideation workshop on some of the remaining research questions of the ACCIO project. Next, we also presented the research insights to the institutions that supported us during the fieldwork in step 3 (understanding the current practices). Finally, we also held a workshop with people interested in ontologies in Flemish industry to discuss their needs to use ontologies in industry. 


\section{Reflections}

At the end of a project time and effort becomes scarce. Activities looking for new opportunities, beside the obligatory wrap up activities can stimulate this phase. In our experience, the pitfall is that these activities are not explicitly detailed in the work plan as discussed in step 1.

This final step is, like the first two steps, not part of the learning cycle as described by Limonard and Koning (2005). We think that this reflective step is, however, in line with their idea around interdisciplinary work and including the social in the design of new technologies.

\section{Open Problems}

In this part, we will go into some of the challenges that we frequently faced with when using the 'innovation binder'. Since the different types of scenarios form the spine of the process, some of the open problems are related to them. Others problems are related to the teamwork and the neetings.

\section{Over-dependency on a sunny day scenario}

As we explained, the first scenarios are sunny day scenarios. It is often tempting to concentrate only on them, and not develop cloudy weather scenarios. It is necessary to consider the failures in the system and the non-use of the user or alternative uses throughout the process. Thinking about the 'cloudy weather' scenarios will result in another, more critical look on the technology under development.

\section{Countering the horror scenario}

During the iterations on the future scenario, the project team will experience the difficulties in finding a balance between the affordances of the pervasive health solution and the interests of the users. Often there is a moment when the future scenario turns into a description of a future experience that seems highly unwanted and not desirable for the end users. Often 'by accident' the team might have created a horror scenario. The story might for instance describe a system that results in a high loss of control. Thus, because the system gives too little freedom to the user, the quality of life tends to decrease. However, such a moment is very functional, because it lets the team question the basic assumptions made in the project. This makes it possible to delay path dependency, e.g., earlier choices dic- 
tating the path you follow (Bijker 1997) as long as possible. To escape the horror scenario and get back to describing a desired future, the team has to focus on the key human values the pervasive system is overruling, and insert more human agency in the system.

\section{Scenarios are not actively used by partners, the story is too long or detailed}

The scenarios could be abandoned during the project when the feeling rises that they are too clumsy or time consuming. Typically one reduces the story to a list of requirements, losing the contextual and relational information the story offers. Again, a search for balance is the solution here. The list of functionalities or functional requirements could be tagged on the different scenes of the scenario. The scenes are parsed into one action or interaction per scene (one or two sentences). When there are changes in the scenario and scenes are added, sub numbering (e.g., 1.a, 1.b) should be used for consistency. In this way, lists and reduction is possible, without losing the connection to the story and the personas in the discussions. Another well-documented trick in literature is visualizing the personas and their stories (e.g., Pruijt \& Aldin, 2003; Jacobs et al., 2008).

The degree of detail of the story can also create difficulties. Especially at the start of the project, one wants to keep openness in the technical solution. Therefore, it is good to try to delay those detailed technical choices until the convergence phase, and then work them out (for example, which screens and devices are involved, how do we in detail organize the access control, what will be the procedure, etc.).

\section{Balance between openness and closure, and the waiting game ?}

The 'innovation binder' process in its design tries to let the social and technical stream work concurrently by stimulating a pendulum between technology push and social pull into a mutual shaping process. In practice, keeping this balance is difficult. Questions that are frequently asked include the length of every step in the process, and how to determine if the scenario is sufficiently stable to start implementing. Typically, the social research stream could go on in digging deeper into the current practices and exploring other future options via co-creation. They are thus reluctant to stabilize the scenario that quickly, since this makes going back on previous choices harder or even impossible (path dependency). A scenario is after all always a condensed modeled representation of the observations and interpretations of the world, and therefore incomplete. The project team should remain aware of this shortcoming and keep the missed variation in mind during develop- 
ment. As such, it is fundamental in the introduction phase of the innovation binder and during the meetings to remind all partners on the dialectical mutual shaping process: choices are to be made, together each partner brings their expertise and waiting for each other should be avoided and at least made explicit.

\section{No interest in trying the innovation binder approach}

Even when the 'innovation binder' approach is explicitly part of the proposal, it sometimes becomes clear that there is no genuine interest of the project partners (or even the project lead) to work in an integrated interdisciplinary way. We reeommend trying to convince the other project partners at the start of the project. But when acceptance is not feasible, it is probably wiser to change from this interdisciplinary approach towards a multidisciplinary way of working(each doing their own research task next to each other) in order to lowery your own degree of frustration. The 'innovation binder' alone will not suffice to work in an interdisciplinary manner. It can only be a supporting tool when project-partners are willing to collaborate, but it cannot enforce it.

Another reason why people are reluctant to use the approach is when the usage domain is too large. Then there are too many practices that are part of the user domain. This usually becomes clear when the hypothetical scenarios are being written and it feels that too much ground needs to be covered. In this case, the project partners need to spend extra time on determining what the central practices are the project wants to focus on.

\section{The team, its scale and different roles}

As in any collaborative undertaking, the classic team dynamics play when making use of the 'innovation binder' approach. So as the rules of thumb of a good focus group learns us, a group over 12 persons is hard to keep together. But in our experience, is still helpful to take the different steps, although the need of one clear owner of the process is more necessary when the group is larger.

Next to the scale, there is the issue of the different roles and their targets with the project. Most researchers in the project will focus on doing research, since their performance is measured by their publications. As such, the implementation work is not as high on their agenda as it is for the participants from the companies and the care organizations. Therefore, it is important in the explication step (step 2) to allow time to understand what makes the other tick. In our experience, a hands-on workshop is more suitable for this: it can be fun, can improve other practical knowledge that is lacking on a certain topic, and it can stimulate bonding. It is important for the success of this workshop that it does not resembles a bad team building activity, which has no relation to the goal of the project. 
A project can strive to involve every necessary actor, but it is unlikely to have every possible role that is needed to make it into a 'real' product. Therefore, it is also important to become aware of missing parties. This can, for instance, be a project partner that delivers content, who does the front-end design and the integration work. Expectations about the final point of the project can thus be altered and made more realistic, and actions can be started during the project to look for other alliances to fill in these gaps. Awareness about the limitations of the project team best comes as early as possible, and is important when the team has to decide which parts of the ideal future scenario should be included in the proof of concept scenario. Things high on the priority list, but unachievable with the current team in the process, should trigger a search for other parties who could help to bring the results closer to valorization in due time (during or after the project).

\section{Documenting the 'innovation binder' process}

Making interdisciplinary choices based on grounded stories is the backbone of the process. Therefore, it is important to document them. In that way, the innovation binder process offers a tool to look back and see the accomplishments and allows going a few steps back and choosing an alternative path. Also, with new participants entering the project due to change of personnel, this documentation is important. However, it is still a challenge to $\% g$ all those decisions in a good way. There are meeting reports of all meetings and different versions of the scenario are kept with comments, but this information) is not that easily accessible due to its volume. As with other documenting task (e.g., code writing and documenting), it is often seen as a burden. Althoughdocumenting needs more attention, one should be careful not to loose the informal character of the meetings revolving around the boundary object of the scenario. Informality in a meeting has a function in itself (Sennett, 2012): finding in a free conversation inspiration and connectedness without formally haking consensus on all details is one of them.

\section{Future Outlook}

Our project timeline is two years, but with another timeline and format the 'innovation binder' approach is likely to be useful as well. The whole approach is grounded in a broader tradition within HCI and PD. To be a practical approach transferable to other projects the approach needs to further mature. This can be achieved by comparing cases empirically and describing what can be altered or improved. For the future improvement of our approach, we want to improve the way we engage project partners or participants who are new to the approach. Another issue to deal with is how to simplify the visualization and documenting of 
the process. By doing this we do not want to loose the informality of meetings and the context of the requirements. Until now, we covered the economical, business side of the development process as part of the social stream, but we want to explore how we can make this perspective more explicit, to focus on the valorization opportunities of the project from the very start. There are certainly elements of AGILE, inspiring this approach. Systematically reviewing how strategies and tactics from this software methodology could inspire in an interdisciplinary R\&D environment need also be done. Finally, we are building more experience with the use of TechCards, trying to understand when and why they work.

Searching for better pervasive health systems, with its vulnerable users and complex context of use, offered us the opportunity and the need to develop this approach and stimulate all partners to come out of their disciplinary comfort zone. If people want to endeavor in pre-competitive research in other domains, this approach could be equally useful.

We want to conclude by stating that the 'innovation binder' approach is able to support the pre-competitive research on pervasive health applications, because it is a tool which is in line with the advice given by Stewart and Claeys (2009): the innovation binder approach is inviting everyone to open up to another world as a team, providing a common ground for discussion and allowing for multiple interpretations and methods from different disciplines.

\section{References}

Ackaert, A., Jacobs, A., Veys, A., Derbeven, J., Gils, M., Buysse, H., and Verhoeve, P. (2009). A Multi-disciplinary Approach towards the Design and Development of Value+ eHomeCare Services. In K. Yogesan, L. Bos, P. Brett, \& M. Gibbons (Eds.), Handbook of Digital Homecare (pp. 243-267). Springer Berlin Heidelberg.

Bijker, W. E. Of Bicycles, Bakelltes and Bulbs: Toward a Theory of Sociotechnical Change. MIT Press, 1997.

Bleumers, L., Jacobs, A. Ongenae, F., Ackaert, A., Sulmon, N., Verstraete, M., and De Zutter, S. (2011). Toward gntology co-creation in institutionalized care settings. In Proceedings of the 5th International Conference on (pp. 559-562). Presented at the Pervasive Health, Dublin: IEEE Xplore Digital Library.

Bødker, S, 2000). Scenarios in user-centred design - setting the stage for reflection and action. Interacting with computers, 13(1), 61-75.

Carro1 J. M. (2000). Five reasons for scenario-based design. Interacting with computers, 13(1), 43-60.

De Rouck, S., Jacobs, A., and Leys, M. (2008). A methodology for shifting the focus of e-health support design onto user needs - A case in the homecare field. International Journal of Medical Informatics, 77, 589-601.

Elprama, S., P. Duysburgh, L. Bleumers and A. Jacobs "Developing assistive technology with multidisciplinary teams: a front-end procedure to stimulate collaboration and manage expectations". In Proceedings of the 12th European Association for the Advancement of Assistive Technology in Europe Conference (AAATE), Vilamoura, Algarve, Portugal, 2013.

Garcia, M. L., \& Bray, O. H. (1997). Fundamentals of technology roadmapping. Sandia National Laboratories Albuquerque, NM. 
Isaksen, S. G., Stead-Dorval, K. B., \& Treffinger, D. J. (2011). Creative approaches to problem solving: a framework for innovation and change. Los Angeles: SAGE.

Jacobs, A., Dreessen, K., and Pierson, J. (2008). “Thick"personas-Using ethnographic Methods for Persona Development as a Tool for Conveying the Social Science View in Technological Design. Observatorio (OBS*), (5), 79-97.

Johansson, M., \& Arvola, M. (2007). A case study of how user interface sketches, scenarios and computer prototypes structure stakeholder meetings. In Proceedings of the 21st British HCI Group Annual Conference on People and Computers: HCI... but not as we know it-Volume 1 (pp. 177-184).

Karasti, Helena, Karen S. Baker, and Geoffrey C. Bowker. "Ecological storytelling and collaborative scientific activities". ACM SIGGROUP Bulletin 23, nr. 2 (2002): 29-30.

Limonard, Sander, Nicole de Koning. "Dealing with Dilemmas in Pre-Competitive ICT

Development Projects: The Construction of 'The Social' in Designing New Technologies". In Everyday Innovators, Leslie Haddon, Enid Mante, Bartolomeo Sapio, Kari-Hans Kommonen, Leopoldina Fortunati, en Annevi Kant (eds.), 168-183. Computer Supported Cooperative Work 32. Springer Netherlands, 2005. http://link.springer.com/chapter/10.1007/1-4020-3872$0 \_11$.

Martin, B., and Hanington, B. M. (2012). Universal methods of design: 10Q Ways to research complex problems, develop innovative ideas, and design effective solutions. Beverly, MA: Rockport Publishers.

Muller, M.J. (2002): Participatory Design: The Third Space in HCL. Cotus Research, Lotus Development Corporation. Cambrigde, MA. U.S.A.

Ocnarescu, Ioana, Frédérique Pain, Carole Bouchard, Améziane Aoussat, and Dominique Sciamma. "Improvement of the industrial design process by the creation and usage of intermediate representations of technology, 'TechCards"'. In Proceedings of the 2011 Conference on Designing Pleasurable Products and Interfaces, 50:1-50:8. DPPI '11. New York, NY, USA: ACM, 2011. doi:10.1145/2347504.2347559.

Ongenae, F., Bleumers, L., Sulmon, N., Verstraete, M., Van Gils, M., Jacobs, A., De Zutter, S., Verhoeve, P., Ackaert, A. and De Turck, F. "Participatory design of a continuous care ontology: towards a user-driven ontology engineering methodology". In Proceedings of the International Knowledge Engineering and Qntology Development Conference (KEOD), 81-90. Paris, France: SciTePress, 2011.

Ongenae, F., Duysburgh, P., Verstraete, M., Sulmon, N., Bleumers, L., Jacobs, A., Ackaert, A., De Zutter, S., Verstichel, S.and De Turck, F. "User-driven design of a context-aware application: An ambient-intelligen nurse call system". In Proceedings of the 6th International Conference on Pervasive Technologies for Healthcare (PervasiveHealth), 205-210. San Diego, CA, USA: IEEE, 2012.

Pagliari, C. (2007). Design and Evaluation in eHealth: Challenges and Implications for an Interdisciplinary Pournal of Medical Internet Research, 9(2).

Pruitt, J. \& Adlin, T. (2005). The Persona Lifecycle: Keeping People in Mind Throughout Product Design, Morgan Kaufmann Publishers Inc., San Francisco, p. 724.

Sennett Richard Together: The Rituals, Pleasures, and Politics of Cooperation New Haven: - Yale University Press, 2012

Schatzki, TR 1997, 'Practices and actions: a Wittgensteinian critique of Bourdieu and Giddens', Philosophy of the Social Sciences, vol. 27, no. 3, 283-308.

Stewart, J., \& Claeys, L. (2009). Problems and Opportunities of Interdisciplinary Work involving Users in Speculative Research for Innovation of Novel ICT Applications. In S. B. (Ed.), (Vol. I). Presented at the COST298 The Good, The Bad and The Challenging. The user and the future of information and communication technologies, Koper, Slovenia: ABS-Center.

Star, Susan Leigh. "This Is Not a Boundary Object: Reflections on the Origin of a Concept". Science, Technology \& Human Values 35, nr. 5 (9 januari 2010): 601-617..

Rip, Arie, Thomas J. Misa, en Johan Schot. Managing Technology in Society: The Approach of Constructive Technology Assessment. Pinter Publishers, 1995. 
Van Bemmel, J. H. (2008). Medical Informatics Is Interdisciplinary avant la Lettre: Methods of Information in Medicine. doi:10.3414/ME9119

Ziefle, M., Röcker, C., Holzinger, A. (2014). Current Trends and Challenges for Pervasive Health Technologies: From Technical Innovation to User Integration. In: Pervasive Health: State-of-the-Art \& Beyond. [Page numbers will be inserted by Springer later on]

\section{Reading}

Nielsen, L. (2013). Personas - User Focused Design. London : Springer-Verlag.

Carroll, J. M. (1995). Scenario-based design: envisioning work and technology insystem development. Wiley. 